
${ }^{18}$

Supporting Information

\title{
Macroalgal Blooms Trigger Breakdown of Seagrass Blue Carbon
}

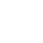

Songlin Liu ${ }^{1 *}, 2,3 \dagger$, Stacey M. Trevathan-Tackett ${ }^{3 \dagger}$, Carolyn J. Ewers Lewis ${ }^{3,4}$, Xiaoping Huang ${ }^{1 *}, 2$, Peter I. Macreadie ${ }^{3}$

(1)

${ }^{1}$ Key Laboratory of Tropical Marine Bio-resources and Ecology, South China Sea Institute of Oceanology, Chinese Academy of Sciences, Guangzhou 510301, China

${ }^{2}$ Innovation Academy of South China Sea Ecology and Environmental Engineering, Chinese Academy of Sciences, Guangzhou 510301, China

${ }^{3}$ School of Life and Environmental Sciences, Centre for Integrative Ecology, Burwood, Deakin University, Victoria 3125, Australia

${ }^{4}$ Department of Environmental Sciences, University of Virginia, Charlottesville, Virginia 22911, United States of America

$\dagger$ These authors contributed equally to this work.

* Corresponding authors:

Xiaoping Huang: South China Sea Institute of Oceanology, Chinese Academy of Sciences, Guangzhou 510301, China, E-mail: xphuang@scsio.ac.cn

Songlin Liu: South China Sea Institute of Oceanology, Chinese Academy of Sciences, Guangzhou 510301, China, E-mail: liusonglin@scsio.ac.cn

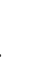
25 26 27 
This Supporting Information (SI) file mainly includes additional information on materials and methods, and supplementary 8 figures and 3 tables with the SI as 17 pages. Seen below:

\section{$>$ Materials and methods}

Additional information on the greenhouse gas flux, detritus elemental content and stable isotope, thermogravimetric, ${ }^{13} \mathrm{C}-\mathrm{NMR}$ and seagrass-associated prokaryotic community analysis.

\section{$>$ Figures}

Figure S1: Photo of mixed seagrass and macroalgal detritus. Figure S2: Variations of detritus elemental contents. Figure S3: Remaining percentages of detritus elemental contents. Figure S4: Variations of detritus stable isotope. Figure S5: Thermograms for the seagrass detritus. Figure S6: OM and TIs. Figure S7: Solid-state ${ }^{13} \mathrm{C}$ NMR spectra of seagrass detritus. Figure S8: Seagrass-associated microbial community composition.

\section{$>$ Tables}

Table S1: Coefficients between principal components analysis (PCA) coordinate axes and seagrass OM quality. Table S2: Comparison of $\alpha$-diversity parameters. Table S3: Specie-level SIMPER analysis. (1) (1)

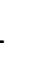
2 3 54 5 56 57 


\section{$\underline{\text { Additional methods information }}$}

Greenhouse gas flux measurement: We gently moved each microcosm, including sediment, detritus mix and the overlying water (without draining), from the main incubation to avoid any disturbance prior to greenhouse gas measurements. The microcosm volume was taken into consideration with each having the same volume $(14 \mathrm{~cm} \times 10 \mathrm{~cm} \times 6 \mathrm{~cm})$. The chambers were clamped closed and connected to the UGGA for $10 \mathrm{~min}$ to measure the changes in $\mathrm{CO}_{2}$ and $\mathrm{CH}_{4}$ concentration. Measurements of $\mathrm{CO}_{2}$ and $\mathrm{CH}_{4}$ concentrations in parts per million (ppm) were taken at 5 second intervals during the 10 minute contact period (96 individual measurements per sample) of each sediment-litter microcosm. First 3 4 minutes data were fitted the linear model, linear regression with $r^{2} \geq 0.8$, to calculate the rate (slope) of change in chamber gas concentration ( $\mathrm{ppm} / \mathrm{s}$ ) was then used in the following equation ${ }^{1}$ :

$$
K=\frac{\text { slope } \times F 1 \times F 2 \times V}{S \times F 3}
$$

Where $K$ represents the flux of gas from the seagrass detritus surface to the atmosphere $\left(\mathrm{mmol} \mathrm{m} \mathrm{m}^{-2} \mathrm{~d}^{-1}\right)$, slope represents the change in chamber gas concentrations over time $\left(\mathrm{ppm} \mathrm{s}^{-1}\right), F 1$ represents the conversion factor from $\mathrm{ppm}$ to $\mathrm{mg} \mathrm{m} \mathrm{m}^{-3}\left(0.65547\right.$ for $\mathrm{CH}_{4}$ and 1.79845 for $\mathrm{CO}_{2}$ ), F2 represents the conversion of seconds to day (86400), $\mathrm{V}$ represents the volume of air within the chamber $\left(\mathrm{m}^{3}\right), S$ represents surface area of the microcosms $\left(\mathrm{m}^{2}\right)$, and $F 3$ represents the conversion from $\mathrm{mg}$ to $\mathrm{mmol}$ (16 for $\mathrm{CH}_{4}$ and 44 for $\mathrm{CO}_{2}$ ). The LGR ${ }^{\mathrm{TM}}$, Ultra-Portable Greenhouse Gas Analyzer converts the $\mathrm{CO}_{2}$ and $\mathrm{CH}_{4}$ concentration at the measuring temperature to the $20{ }^{\circ} \mathrm{C}$ condition. Temperature and ambient pressure were automatically corrected by the UGGA.

Detritus elemental content and stable isotope analysis: Elemental carbon (C) and nitrogen $(\mathrm{N})$ content was analyzed using an Elemental CHNS analyzer model Vario EL cube (Vario EL, Elemental Analyser system GmbH, Germany). $\delta^{13} \mathrm{C}$ and $\delta^{15} \mathrm{~N}$ were analyzed on an isotope ratio mass spectrometer (Thermo Scientific MAT 253). All isotopic data were expressed in the conventional delta notation (\%o): $\delta^{13} \mathrm{C}_{\text {sample }}$ or $\delta^{15} \mathrm{~N}_{\text {sample }}=\left(\mathrm{R}_{\text {sample }} / \mathrm{R}_{\text {reference }}-1\right) \times 1000$ where $\mathrm{R}={ }^{13} \mathrm{C} /{ }^{12} \mathrm{C}$ or ${ }^{15} \mathrm{~N} /{ }^{14} \mathrm{~N}$. The reference standard was Peedee Belemnite for $\delta^{13} \mathrm{C}$ and atmospheric $\mathrm{N}_{2}$ for $\delta^{15} \mathrm{~N}$, respectively. 
Analysis uncertainty was $\leq 0.2 \%$.

Thermogravimetric analysis (TGA): The $\mathrm{TI}_{1}$ (labile; soluble carbohydrates, hemicellulose) ranged from $180{ }^{\circ} \mathrm{C}$ to $300{ }^{\circ} \mathrm{C} . \mathrm{TI}_{2}$ (cellulose-associated recalcitrant organic matter) extended from $300{ }^{\circ} \mathrm{C}$ to $400{ }^{\circ} \mathrm{C}$, then from $400{ }^{\circ} \mathrm{C}$ to $600{ }^{\circ} \mathrm{C}$ was determined as $\mathrm{TI}_{3}$ (lignin-associated recalcitrant organic matter and insoluble polysaccharide residues). The range of mass loss $\left(\mathrm{TI}_{1-3}\right)$ was recalculated as a portion of total organic matter (OM) from $180^{\circ} \mathrm{C}$ to $600{ }^{\circ} \mathrm{C}$.

${ }^{13}$ C-NMR analysis: The replicate samples from each treatment and time point (before and after incubation) were mixed as a sample and then weighed (70 80 mg). Samples were packed into $4 \mathrm{~mm}$ diameter zirconia rotors with Kel-F end caps and spun at 10 $\mathrm{kHz}$. The cross-polarization analyses used a $3.9 \mu \mathrm{s}, 90^{\circ}$ pulse, a contact time of $1.5 \mathrm{~ms}$, and a recycle time of $2 \mathrm{~s}$ was used for all samples with 4000 scans collected for each sample. All spectral processing was completed using the Bruker TopSpin 2.1 software after phasing and baseline corrections were applied. ${ }^{2}$ The acquired NMR spectral intensity was divided into a series of chemical shift regions: amide/carboxyl/ketone (215-165 ppm), O-aryl (165-145 ppm), aryl (145-110 ppm), di-O-alkyl (110-95 ppm), O-alkyl (95-60 ppm), Nalkyl/methoxy (60-45 ppm) and alkyl (45-10 ppm) ${ }^{3,4}$. Further, the signal intensity of each sample was integrated across the spectral regions, the alkyl to O-alkyl ratio was calculated and then entered in a molecular mixing model (MMM) for terrestrial soils to predict macromolecule composition (carbohydrate, protein, lignin, lipid, and carbonyl) of the seagrass detritus ${ }^{5}$. This model has been altered to apply in the seagrass amino acid content research ${ }^{3,6}$. The model was constrained based on the elemental carbon $(\mathrm{C})$ and nitrogen $(\mathrm{N})$ content results of the tissues in this study.

Seagrass-associated prokaryotic community analysis: Seagrass tissue $(\sim 0.20 \mathrm{~g}$ WW) was extracted using the Qiagen DNA PowerSoil extraction kit. The gDNA was normalised to $5 \mathrm{ng} \mu \mathrm{L}^{-1}$ before running triplicate PCRs using 16S rRNA modified V4 515f-806r primers and the following PCR methods: $94{ }^{\circ} \mathrm{C}$ for $3 \mathrm{~min}, 25$ cycles $\left(94{ }^{\circ} \mathrm{C}\right.$ for $30 \mathrm{~s}, 50{ }^{\circ} \mathrm{C}$ for $30 \mathrm{~s}, 72{ }^{\circ} \mathrm{C}$ for $30 \mathrm{~s}$ ) and $72{ }^{\circ} \mathrm{C}$ for $5 \mathrm{~min}$. The PCR products were pooled and cleaned using AmPure beads, before indexing and sequencing on the 
117 Illumina MiSeq. Bioinformatics was performed using QIIME2 v2019.7 with DADA2

118 pipeline. After normalizing to 20,400 reads, alpha diversity (Amplicon sequence

119 variants -ASV-richness, Shannon Index, Pielou Eveness) and beta diversity (weighted

120 UniFrac distance matrix) were calculated. ASVs were classified using the Silva 99\%

$121 \quad 515-806$ v 132 database.

\section{Literature Cited}

123 1. Lambert, M.; Fréchette, J. L., Analytical Techniques for Measuring Fluxes of CO2 and CH4 from 124 Hydroelectric Reservoirs and Natural Water Bodies. 2005; p 37-60.

125 2. Baldock, J. A.; Sanderman, J.; Macdonald, L. M.; Puccini, A.; Hawke, B.; Szarvas, S.; McGowan,

126 J., Quantifying the allocation of soil organic carbon to biologically significant fractions. Soil Research 127 2013, 51, (8), 561-576.

128 3. Trevathan-Tackett, S. M.; Macreadie, P. I.; Sanderman, J.; Baldock, J.; Howes, J.; Ralph, P., A 129 global assessment of the chemical recalcitrance of seagrass tissues: implications for long-term carbon 130 sequestration. Frontiers in Plant Science 2017, 8, 925.

131 4. Macreadie, P. I.; Trevathan-Tackett, S. M.; Baldock, J. A.; Kelleway, J. J., Converting beach-cast 132 seagrass wrack into biochar: A climate-friendly solution to a coastal problem. Science of The Total 133 Environment 2017, 574, 90-94.

134 5. Baldock, J. A.; Masiello, C. A.; Gélinas, Y.; Hedges, J. I., Cycling and composition of organic 135 matter in terrestrial and marine ecosystems. Marine Chemistry 2004, 92, (1), 39-64.

136 6. Torbatinejad, N. M.; Annison, G.; Rutherfurd-Markwick, K.; Sabine, J. R., Structural Constituents 137 of the Seagrass Posidonia australis. Journal of Agricultural and Food Chemistry 2007, 55, (10), 138 4021-4026. 
139

140

141

142

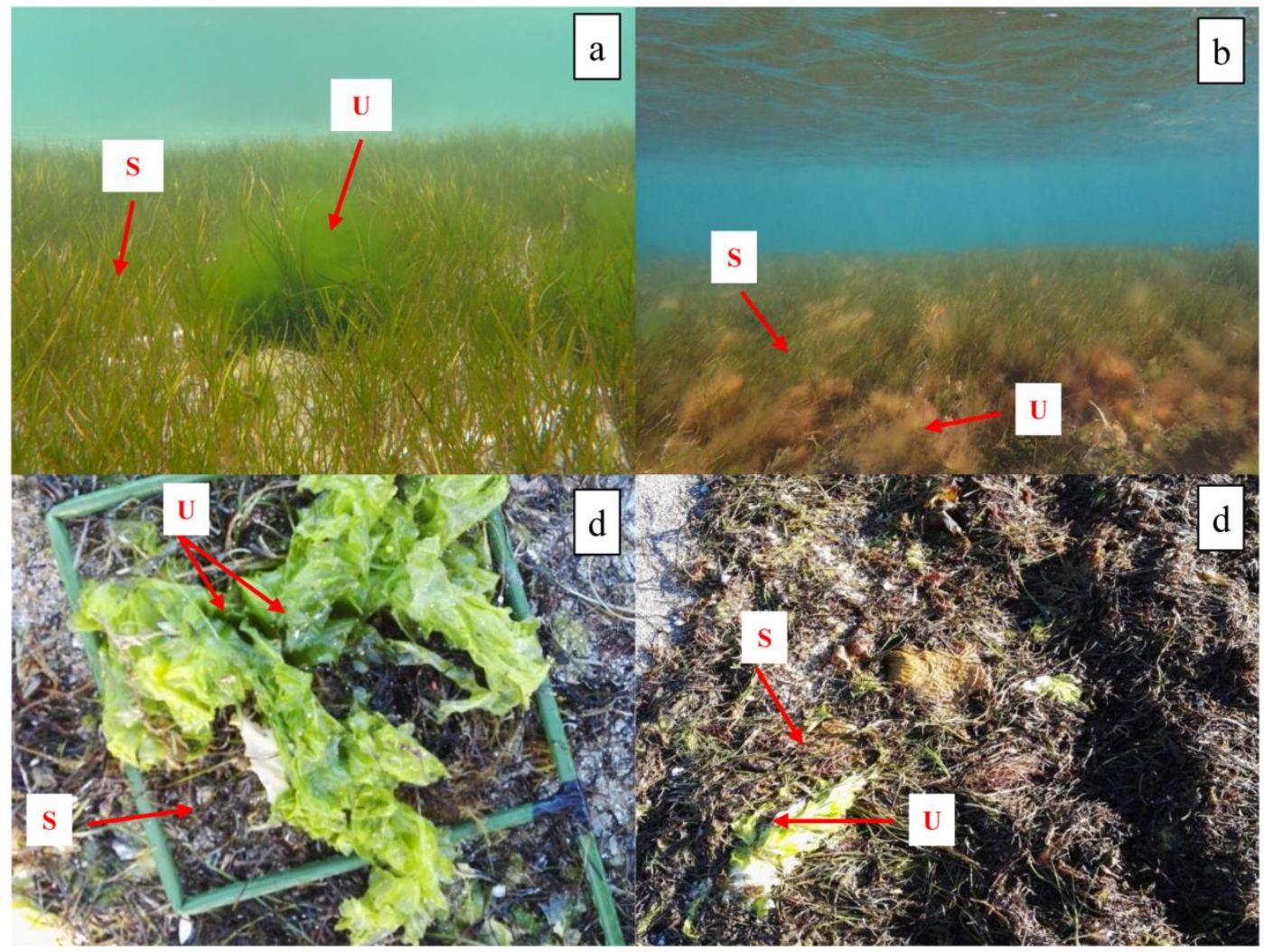

Figure S1. Composed of mixed seagrass and macroalgal detritus observed along the coastal waters and shorelines of Port Phillip Bay, Victoria, Australia. The U and S indicate Ulva and seagrass, respectively. 

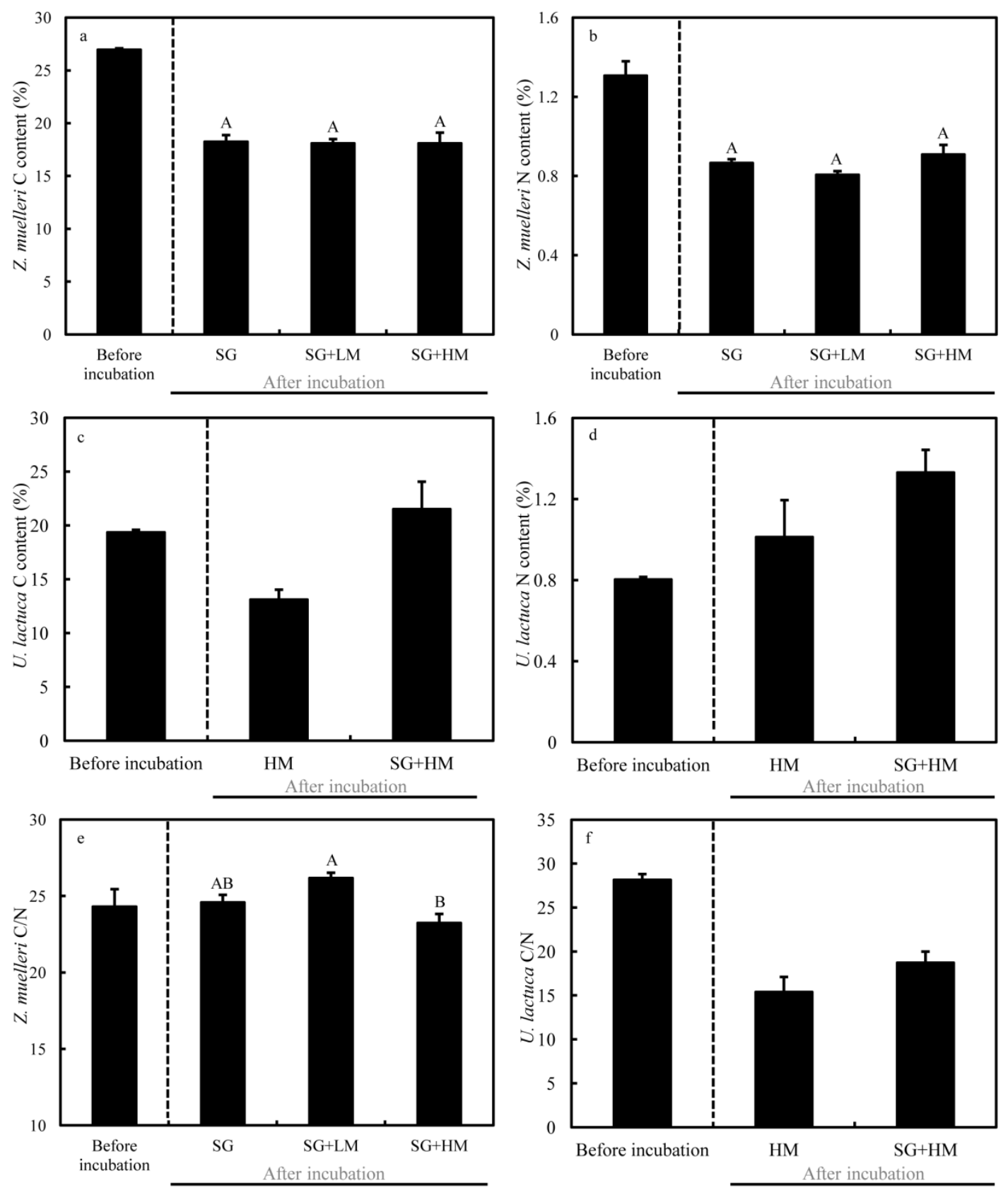

Figure S2. Variations of the Zostera muelleri $\mathrm{C}$ content (a), Z. muelleri $\mathrm{N}$ content (b), Ulva lactuca $\mathrm{C}$ content (c), U. lactuca $\mathrm{N}$ content (d), $\mathrm{C} / \mathrm{N}$ ratios of Z. muelleri (e) and U. lactuca (f) at before and after the incubation (mean \pm S.E.M). The different capital letters over the bars indicate significant differences among the SG, SG+LM and SG+HM groups (S-N-K test, $p<0.05$ ). No significant differences of $U$. lactuca $\mathrm{C}, \mathrm{N}$ and $\mathrm{C} / \mathrm{N}$ ratios were observed between $\mathrm{HM}$ and $\mathrm{SG}+\mathrm{HM}$ (c, d, f) (Student's $t$-test, $p>0.05$ ). 

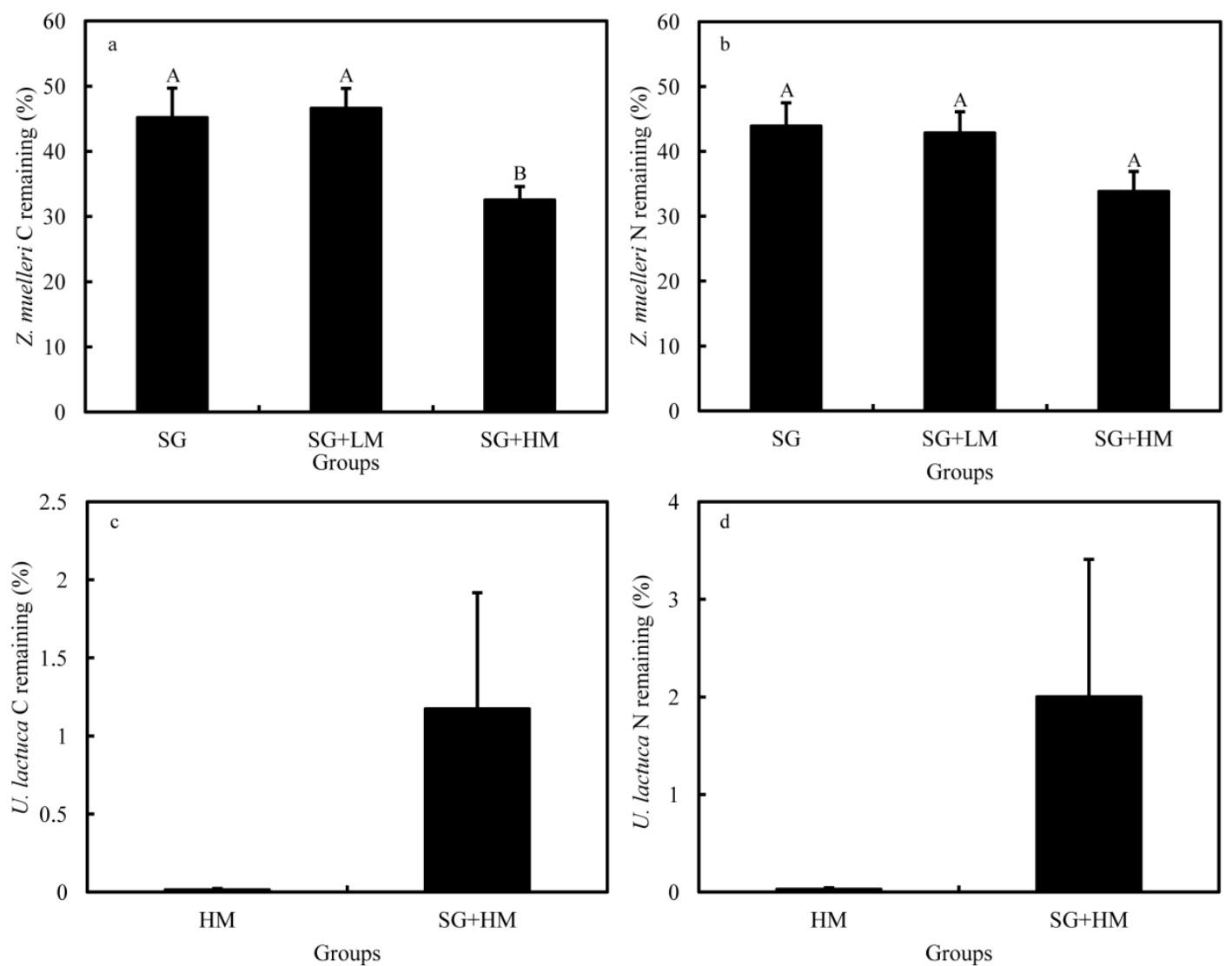

Figure S3. Remaining percentages of Zostera muelleri carbon (a), Z. muelleri nitrogen (b), Ulva lactuca carbon (c) and U. lactuca nitrogen (d) after 62-days of decomposition comparing to the starting Z. muelleri and $U$. lactuca carbon and nitrogen contents. The different capital letters over the bars indicate significant differences among the groups of $\mathrm{SG}, \mathrm{SG}+\mathrm{LM}$ and $\mathrm{SG}+\mathrm{HM}$ (S-N-K test, $p<0.05$ ). No significant differences were observed between $\mathrm{HM}$ and $\mathrm{SG}+\mathrm{HM}$ (c, d) (Student's $t$-test, $p>0.05$ ). Values represent means \pm S.E. 

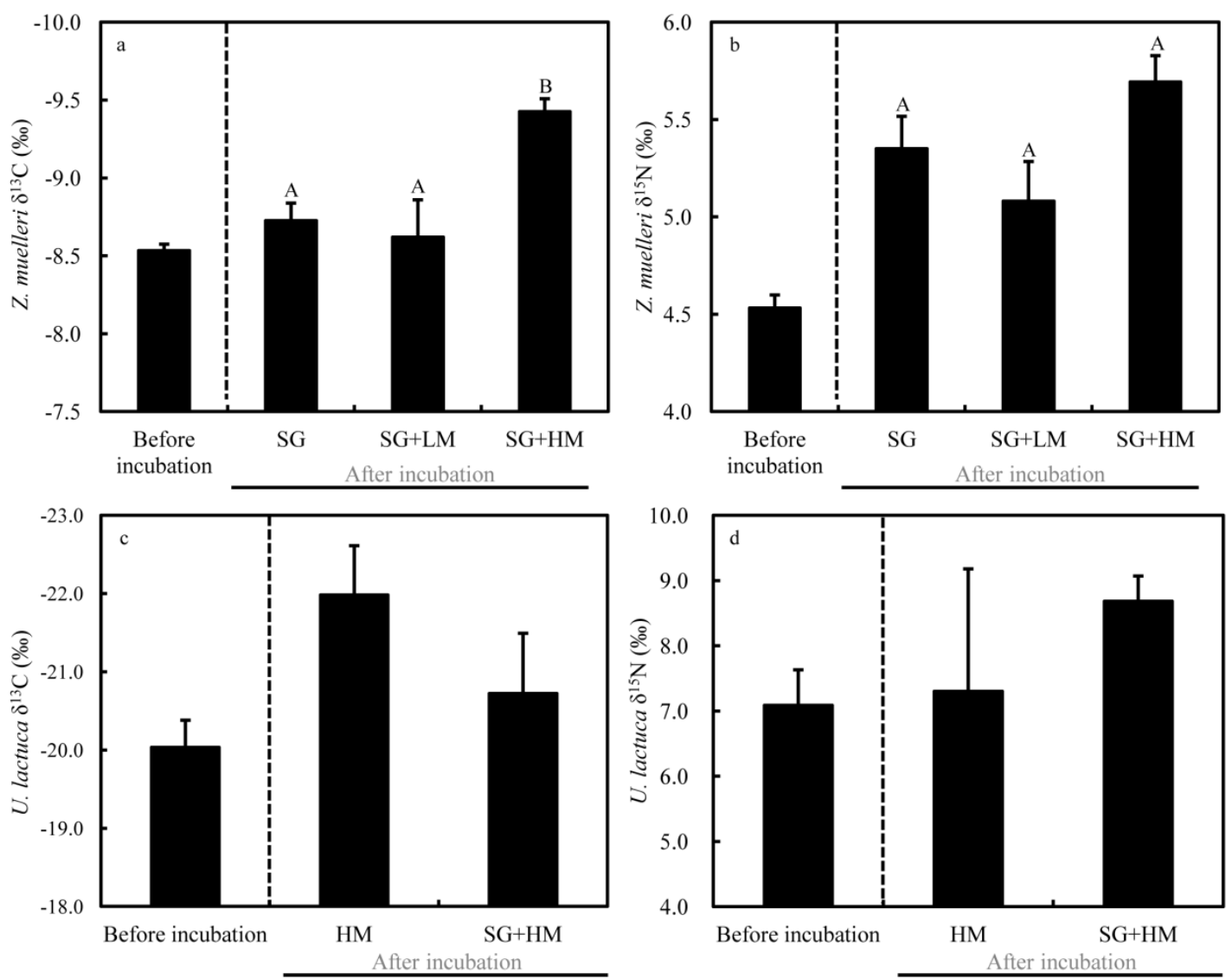

Figure S4. Variations of the Zostera muelleri $\delta^{13} \mathrm{C}(\mathrm{a})$, Z. muelleri $\delta^{15} \mathrm{~N}(\mathrm{~b})$, Ulva lactuca $\delta^{13} \mathrm{C}(\mathrm{c})$, and $U$. lactuca $\delta^{15} \mathrm{~N}$ (d) before and after 62-days of decomposition (mean \pm S.E.M). The different capital letters over the bars indicate significant differences among the SG, SG+LM and SG+HM groups ( $\mathrm{S}-\mathrm{N}-\mathrm{K}$ test, $p<0.05$ ). No significant differences were observed between HM and $\mathrm{SG}+\mathrm{HM}$ (c, d) (Student's $t$-test, $p>0.05$ ). 

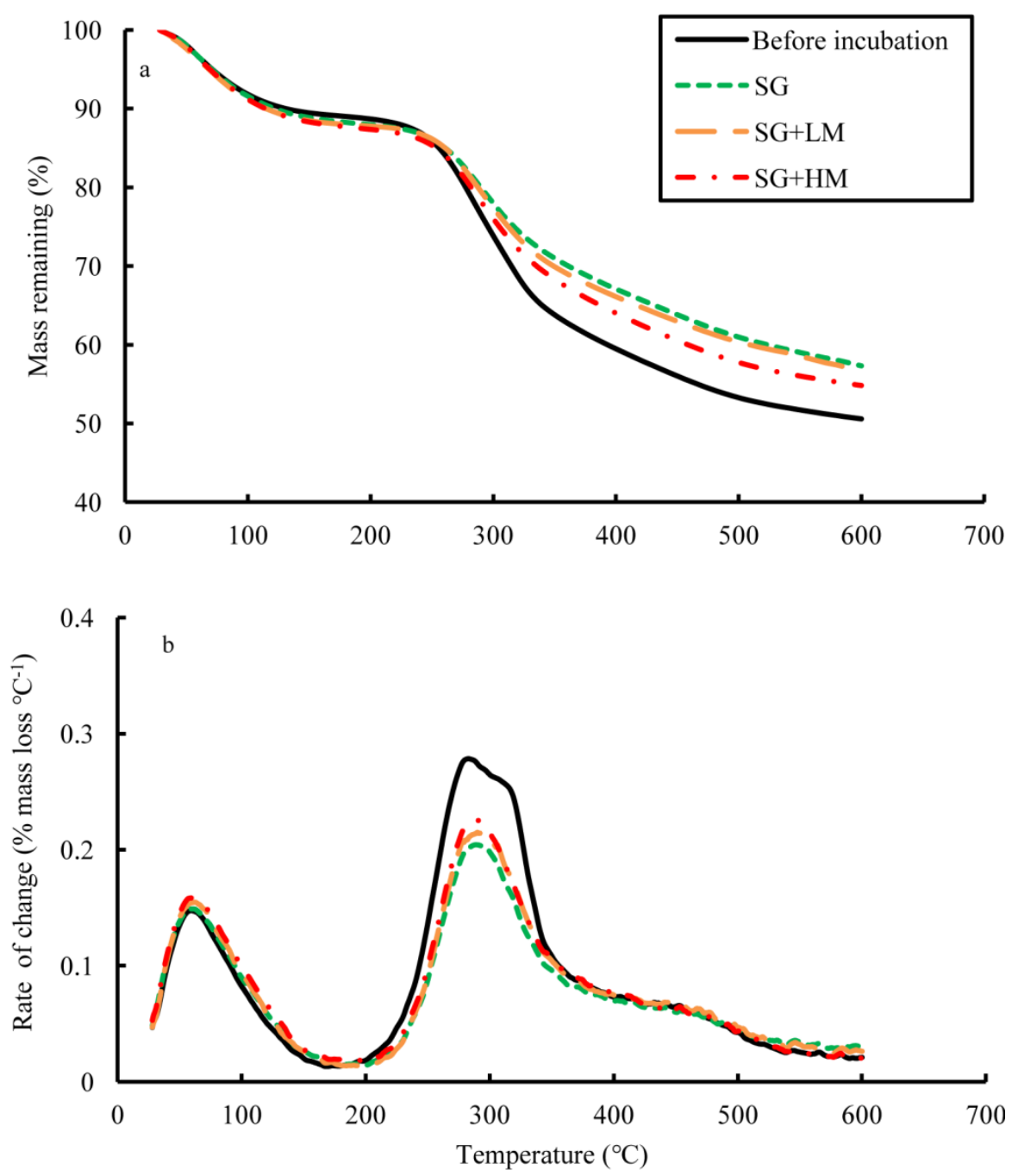

171

172 Figure S5. Thermograms for the seagrass detritus of the before and after incubation (SG, SG+LM, 173 and $\mathrm{SG}+\mathrm{HM}$ groups), (b) \% mass remaining with increasing temperature and (b) derivate rate-of-change ( $\%$ mass loss per ${ }^{\circ} \mathrm{C}$ ) with increasing pyrolysis temperature. 

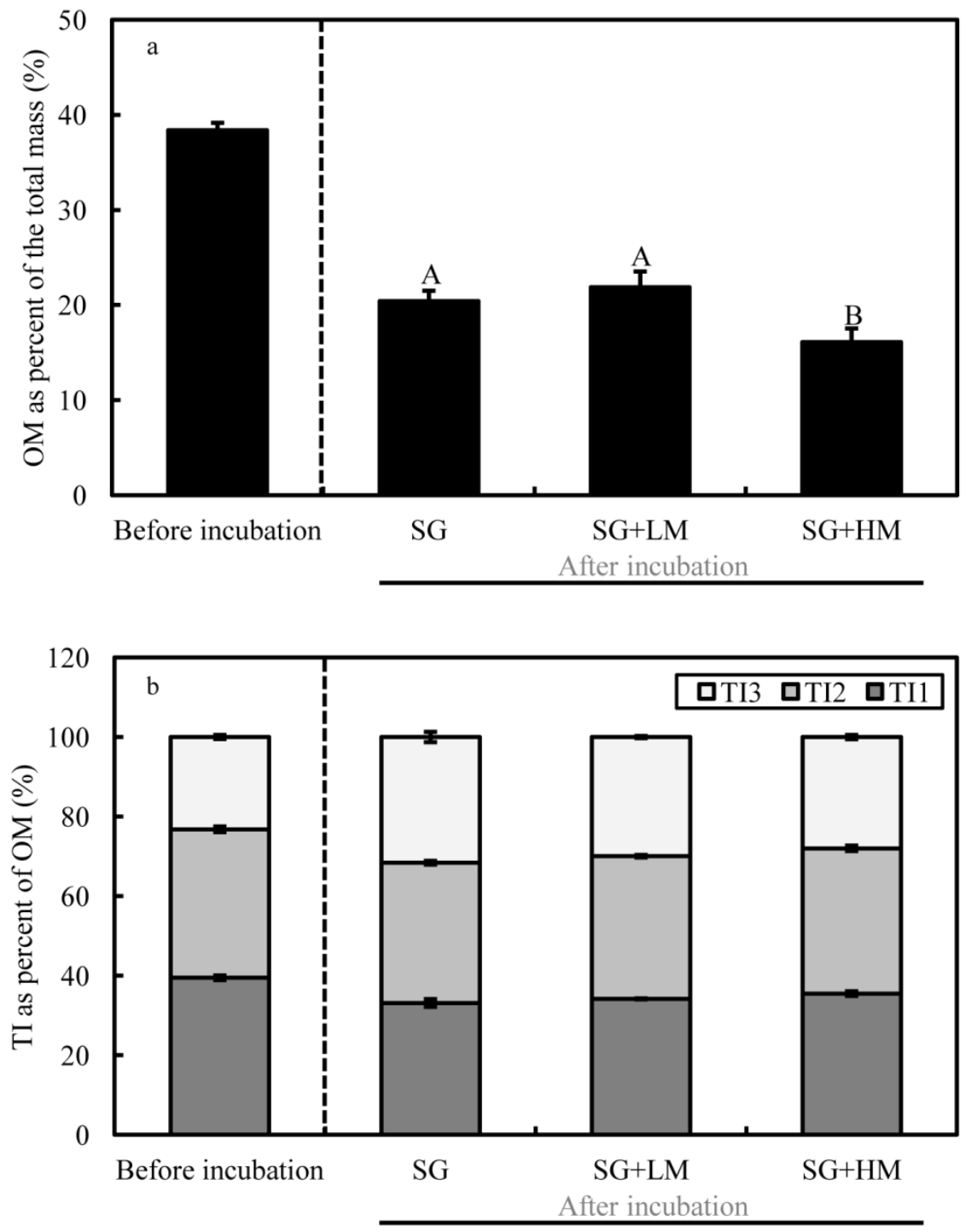

Figure S6. OM as percent of the total mass (a) and thermal intervals (TI) as percent of OM (b) before and after 62-days of decomposition. TIs represent distinct organic matter components from TGA ( $\mathrm{TI}_{1}$ : labile, carbohydrates, hemicellulose, $180^{\circ} \mathrm{C}-300 \quad{ }^{\circ} \mathrm{C} ; \mathrm{TI}_{2}$ : cellulose-associated recalcitrant organic matter, $300^{\circ} \mathrm{C}-400{ }^{\circ} \mathrm{C}$; $\mathrm{TI}_{3}$ : refractory, lignin-associated recalcitrant organic matter and residues, $\left.400{ }^{\circ} \mathrm{C}-600{ }^{\circ} \mathrm{C}\right)$. Values represent mean \pm S.E.

Table S1. Coefficients between principal components analysis (PCA) coordinate axes and seagrass OM quality using thermogravimetric analyses.

\begin{tabular}{ccc}
\hline Variable & $\mathrm{PC} 1$ & $\mathrm{PC} 2$ \\
\hline $\mathrm{TI}_{1}$ & -0.565 & 0.616 \\
$\mathrm{TI}_{2}$ & -0.495 & -0.782 \\
$\mathrm{TI}_{3}$ & 0.660 & -0.062 \\
\hline
\end{tabular}



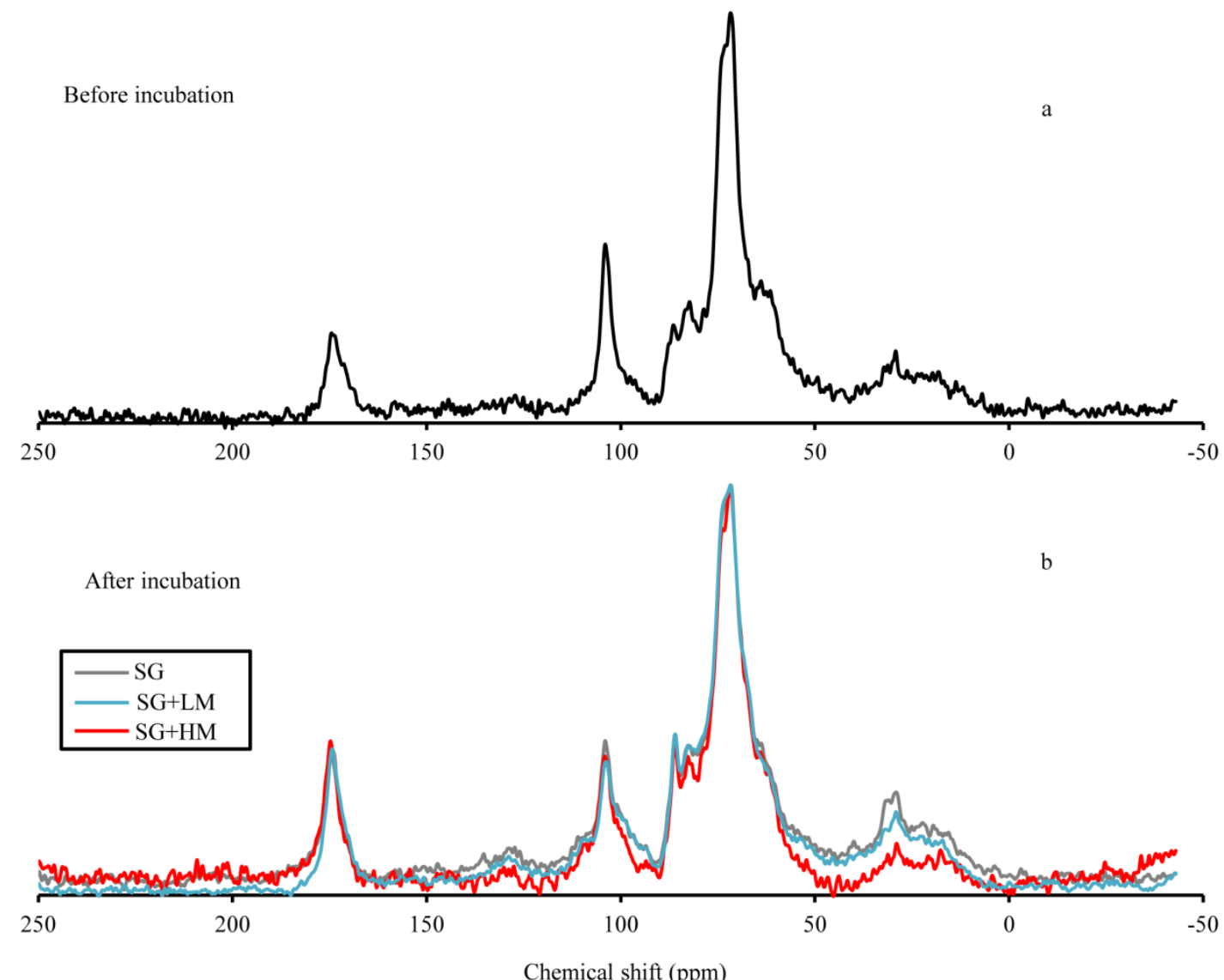

Chemical shift (ppm)

188 Figure S7. Solid-state ${ }^{13} \mathrm{C}$ NMR spectra acquired for the seagrass detritus of before incubation (a)

189 and after incubation (b).

190

Table S2. $t$-values of student's $t$-test ( with $p$ values shown in brackets) between SG and SG+HM

192 groups, and between before the incubation and after incubation (SG and SG+HM groups) for 193 different diversity parameters.

\begin{tabular}{cccc}
\hline Group comparison & Richness $S$ & Shannon-Wiener's $H^{\prime}$ & Evenness \\
\hline SG $v s . \mathrm{SG}+\mathrm{HM}$ & $0.268(0.798)$ & $0.081(0.938)$ & $0.538(0.610)$ \\
$\begin{array}{c}\text { Before incubation } v s . \\
\text { after incubation }\end{array}$ & $0.845(0.418)$ & $0.606(0.558)$ & $0.114(0.911)$ \\
\hline
\end{tabular}




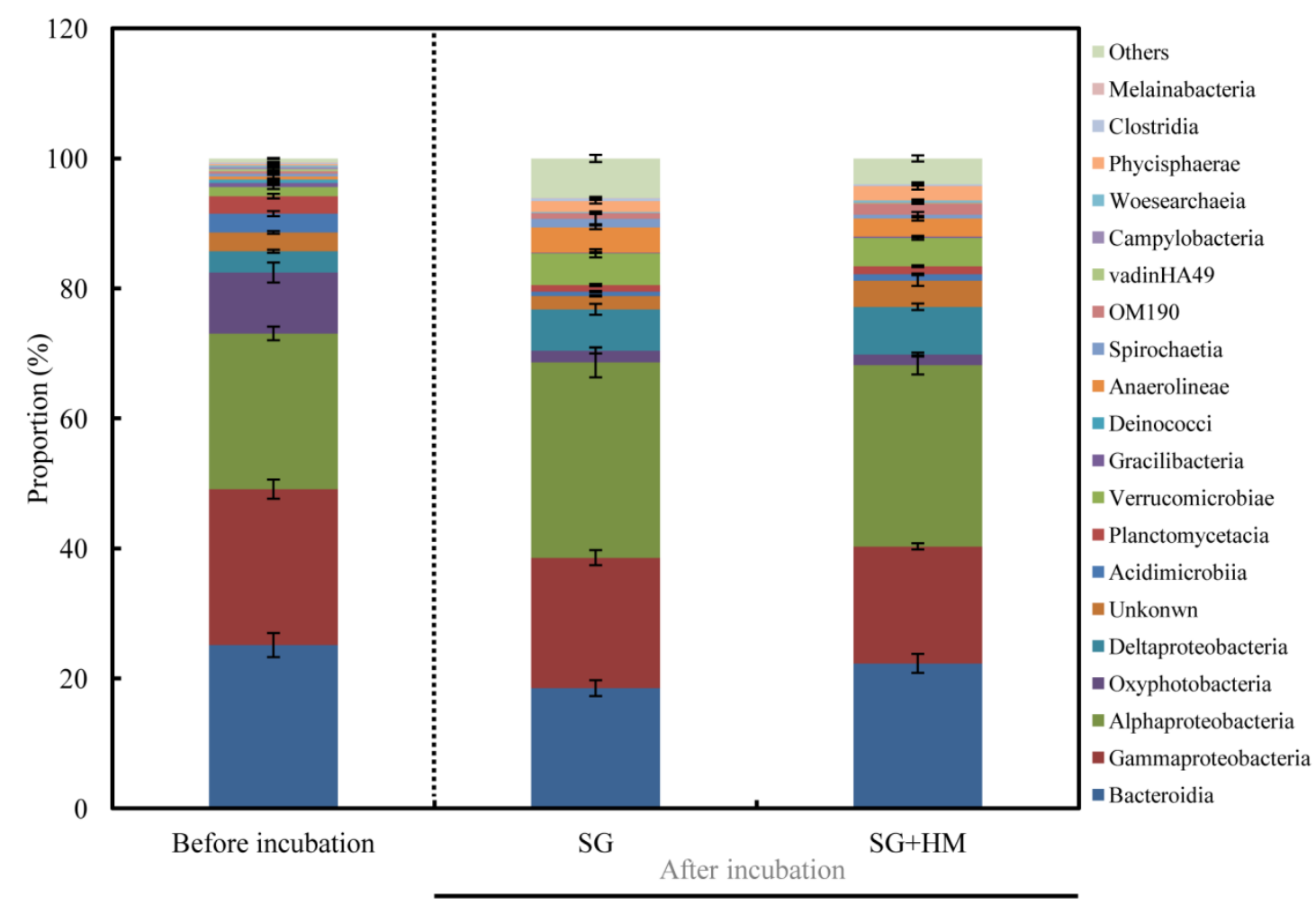

Figure S8. Seagrass-associated microbial community composition of the top 20 most abundant 197 classes averaged over before and after incubation ( $\mathrm{SG}$ and $\mathrm{SG}+\mathrm{HM}$ groups). Values show means \pm 198 S.E. $(\mathrm{n}=4)$. 
Table S3. Results of the specie-level SIMPER analysis giving the dissimilarities of total bacterial communities between before and after incubation. The top 50\% on ASVs that contributing to the dissimilarity are listed (abundance values are square root transformed). SD represents standard deviation.

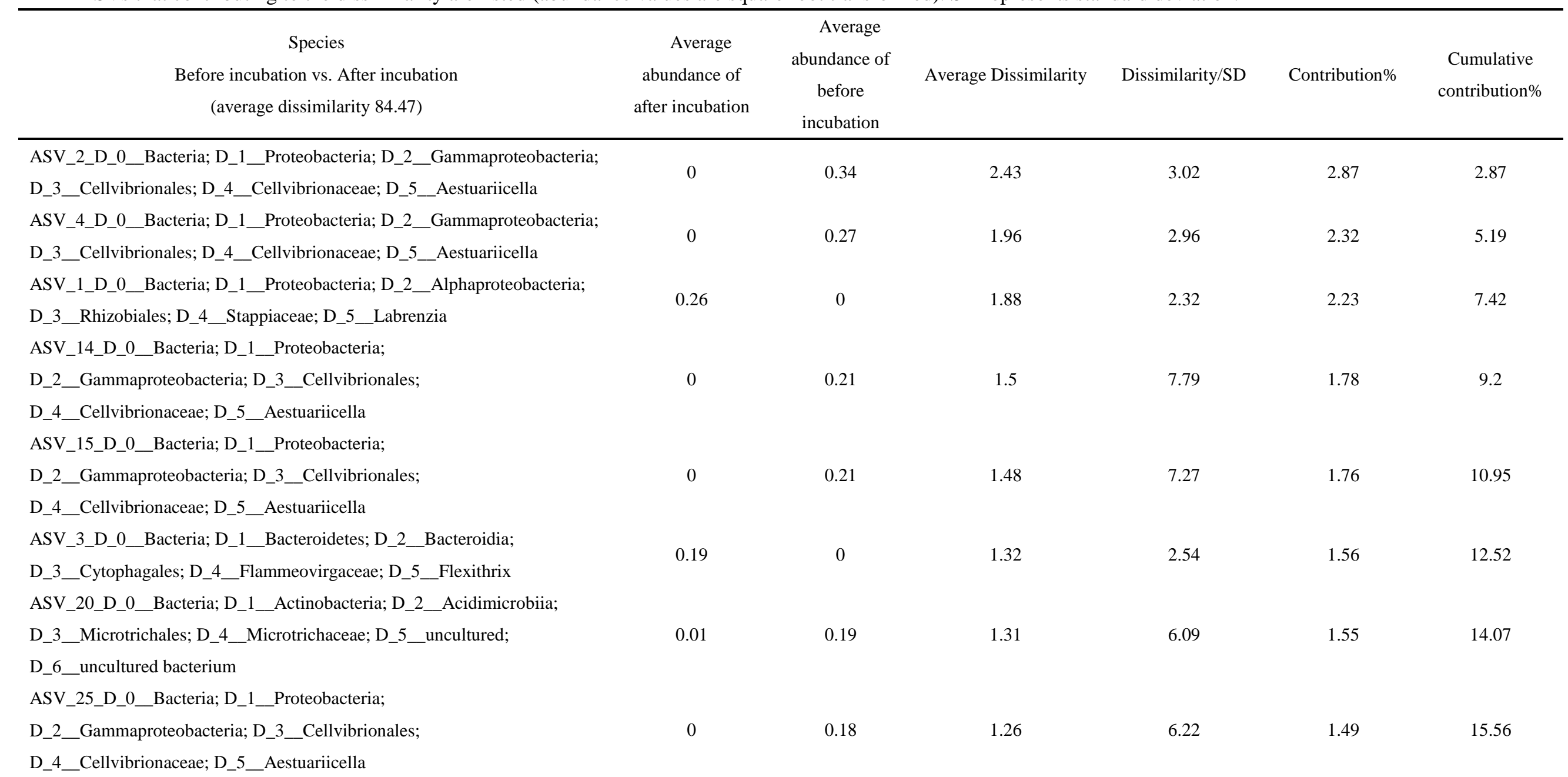


ASV_7_D_0__Bacteria; D_1_Proteobacteria; D_2_Alphaproteobacteria; D_3_Rhizobiales; D_4_Stappiaceae; D_5_Labrenzia

D_2_Gammaproteobacteria; D_3_Oceanospirillales; D_4_Nitrincolaceae

ASV_12_D_0_Bacteria; D_1__Proteobacteria; D_2__Deltaproteobacteria;

D_3_Myxococcales; D_4_BIrii41; D_5_uncultured bacterium;

ASV_11_D_0_Bacteria; D_1__Proteobacteria; D_2_Alphaproteobacteria; D_3_Rhizobiales; D_4_Stappiaceae; D_5_Labrenzia

D_2_Gammaproteobacteria; D_3_Thiohalorhabdales;

D_4_Thiohalorhabdaceae; D_5_Granulosicoccus; D_6_uncultured

bacterium

ASV_31_D_0_Bacteria; D_1_Cyanobacteria; D_2_Oxyphotobacteria;

\section{D_3_Chloroplast}

D_2_Gammaproteobacteria; D_3_tThiohalorhabdales;

D_4_Thiohalorhabdaceae; D_5_Granulosicoccus; D_6_uncultured 
ASV_17_D_0_Bacteria; D_1_Proteobacteria; D_2_Alphaproteobacteria; D_3_Rhizobiales; D_4_Stappiaceae; D_5_Labrenzia

ASV_10_D_0_Bacteria; D_1__Proteobacteria; D_2_Alphaproteobacteria; D_3_Rhizobiales; D_4_Stappiaceae; D_5_Labrenzia

ASV_19_D_0_Bacteria; D_1__Proteobacteria; D_2_Alphaproteobacteria;

D_3_thalassobaculales; D_4_Nisaeaceae; D_5_Nisaea

ASV_16_D_0_Bacteria; D_1_Bacteroidetes; D_2_Bacteroidia;

D_3_Cytophagales; D_4_Flammeovirgaceae; D_5_Flexithrix

ASV_59_D_0_Bacteria; D_1_Bacteroidetes; D_2_Bacteroidia;

D_3_Cytophagales; D_4_Cyclobacteriaceae; D_5_Ekhidna

ASV_5_D_0_Bacteria; D_1_Proteobacteria; D_2_Alphaproteobacteria;

D_3_Rhizobiales; D_4_Stappiaceae; D_5_Labrenzia

ASV_53_D_0_Bacteria; D_1_Actinobacteria; D_2_Acidimicrobiia;

D_3_Microtrichales; D_4_Microtrichaceae; D_5_uncultured;

D_6_uncultured bacterium

ASV_21_D_0_Bacteria; D_1_Bacteroidetes; D_2_Bacteroidia;

D_3_Cytophagales

ASV_57_Unassigned

ASV_27_D_0_Bacteria; D_1__Chloroflexi; D_2_Anaerolineae;

D_3 SBR1031; D_4_A4b

ASV 23_D 0 B Bacteria; D_1_Cyanobacteria; D 2 Oxyphotobacteria;

D_3_Chloroplast

ASV_29_D_0_Bacteria; D_1__Proteobacteria; D_2_Alphaproteobacteria

D_3_Thalassobaculales; D_4_Nisaeaceae; D_5_Nisaea

ASV_54_D_0_Bacteria; D_1_Cyanobacteria; D_2_Oxyphotobacteria;

D 3 Chloroplast

10.17

30.93 
ASV_56_D_0_Bacteria; D_1_Cyanobacteria; D_2__Oxyphotobacteria; D_3_Chloroplast

ASV_120_D_0_Bacteria; D_1_Bacteroidetes; D_2_Bacteroidia;

D_3_Cytophagales; D_4_Cyclobacteriaceae

ASV_118_D_0__Bacteria; D_1_Cyanobacteria; D_2_Oxyphotobacteria

D_3_Chloroplast

(112 Proteobacteria;

D_2_Gammaproteobacteria; D_3_Oceanospirillales; D_4_Nitrincolaceae;

ASV_68_D_0_Bacteria; D_1__Proteobacteria;

D_2_Gammaproteobacteria; D_3_Alteromonadales; D_4_Colwelliaceae;

ASV_24_D_0_Bacteria; D_1__Verrucomicrobia; D_2__Verrucomicrobiae; D_3_Opitutales; D_4_Puniceicoccaceae; D_5_Pelagicoccus 